\title{
Multiple Unilobar Bleeds in a Case of Retroviral Disease
}

\author{
Khardenavis $\mathrm{V}^{1}$, Kulkarni $\mathrm{S}^{2}$, Khardenavis $\mathrm{S}^{3}$ and Deshpande $\mathrm{A}^{4 *}$ \\ ${ }^{1}$ Departmemt of Physician, University of Health Sciences, India \\ ${ }^{2}$ Medical Student, University of Health Sciences, India \\ ${ }^{3}$ Senior Resident, Regional Eye Hospital, India \\ ${ }^{4}$ Consultant Neurologist, Vinayaka Neuro Multispecialty Clinic, India
}

Submission: November 23, 2017; Published: December 11, 2017

*Corresponding author: Deshpande A, Vinayaka Neuro Multispecialty Clinic, Shri Krishna Children's Hospital Complex, Vijaya Talkies Road, Hanamakonda, Warangal, 506001, Telangana, India, Tel: +91 8106812222; Email: dr.anirudda.deshpande@gmail.com

\begin{abstract}
Central Nervous System complications of retroviral infection are common. The patho-physiology of many of these complications is still not well understood. In 10-20\% of symptomatic retroviral infections, neurological disease is mostly the primary manifestation of AIDS. Intracerebral hemorrhages seem to be less frequent than cerebral ischemia in retropositive patients, and are often associated with thrombocytopenia, aneurismal or primary CNS lymphoma.

We report a case of multiple unilobar bleeds in retroviral disease patient, the etiology of which is not attributable to the above mentioned causes. We postulate that having ruled out the above mentioned possibilities, HIV associated vasculopathy (HAV) may be the most likely cause of such multiple intracranial bleeds in patients with retroviral disease. To the best of our knowledge, it has been rarely reported in the past. While investigating such bleeds, Susceptibility Weighted Imaging (SWI) MRI is a useful technique to determine additional old hemorrhages (due to hemosiderin deposition). We recommend that Digital Substraction Angiography (DSA) should be done in all such cases, to rule out other cause of bleed such as arteriovenous malformation, aneurysm, Primary CNS Lymphoma.
\end{abstract}

Keywords: Multiple unilobar intracranial bleeds in HIV; Intra-cerebral bleed in HIV

Abbreviations : CNS: Central Nervous System; HIV: Human Immunodeficiency Virus; AIDS: Acquired Immuno Deficiency Syndrome; HAV: HIV associated vasculopathy; DSA: Digital Subtraction Angiography; UMN: Upper Motor Neuron; BP: Blood Pressure; mmHg: millimeters of mercury; Aptt: Activated partial thromboplastin time; PT: Prothrombin Time; INR: International Normalized Ratio; RVD: Retro Viral Disease, ANA: Anti Nuclear Anibodies ; ANCA: Anti Nuclear Cytoplasmic Antibodies

\section{Introduction}

A 55 year male known case of Retroviral disease (RVD) positive illness, on Antiretroviral medications (Zidovudine, Lamivudine and Nevirapine) presented with abrupt onset difficulty in speaking, deviation in angle of mouth to left. On examination, was found to have motor aphasia (non-fluent), impaired repetition, though comprehension was normal. Right Upper Motor Neuron (UMN) facial palsy, brisk Deep tendon reflexes (DTR) on right side with ipsilateral plantar extensor. CT Brain showed Left Frontal lobar hematoma (Figure 1 \& 2). MRI Brain showed left frontal bleed with multiple chronic micro bleeds (Figure 3). Digital Subtraction Angiography [DSA] was normal (Figure 4 \& 5), ruling out any arterio-venous malformations or aneurysms. The patient was not a known case of hypertension. All his blood pressure reading post admission were normal prior to this event. The blood pressure (BP) recorded soon after the onset of neurological deficits was $170 / 100 \mathrm{mmHg}$. HIV 1 was confirmed with western blot test, CD 4 count 940 , other lab reports normal. Coagulation profile activated prothrombin time
(PTT), prothrombin Time (PT), International Normalized Ratio (INR), platelet count were normal. The other investigations included cardiovascular workup (electrocardiogram and echocardiography), chest x ray, bilateral carotid artery Doppler of extra cranial neck vessels, ultrasonography of abdomen and pelvis , CSF analysis and culture.

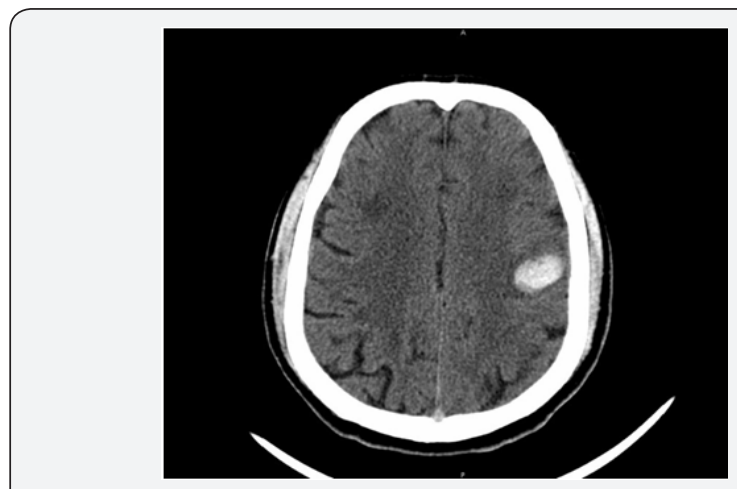

Figure 1: Computerized Tomography (CT) Brain axial view shows left frontal cortical lobar bleed. 


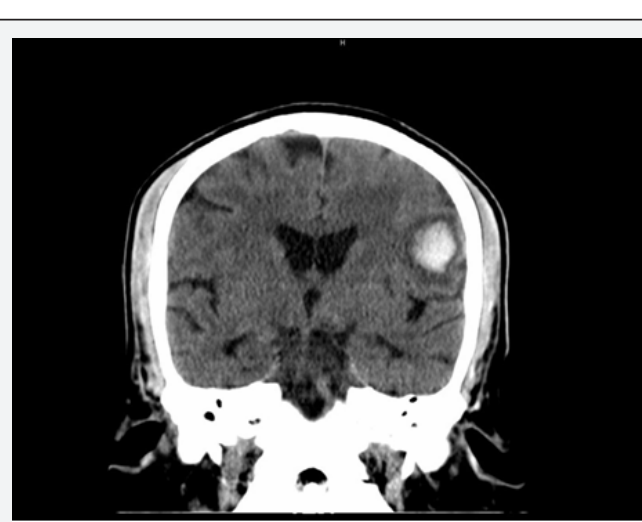

Figure 2: Computerized Tomography (CT) Brain Coronal view showing left frontal cortical lobar bleed.

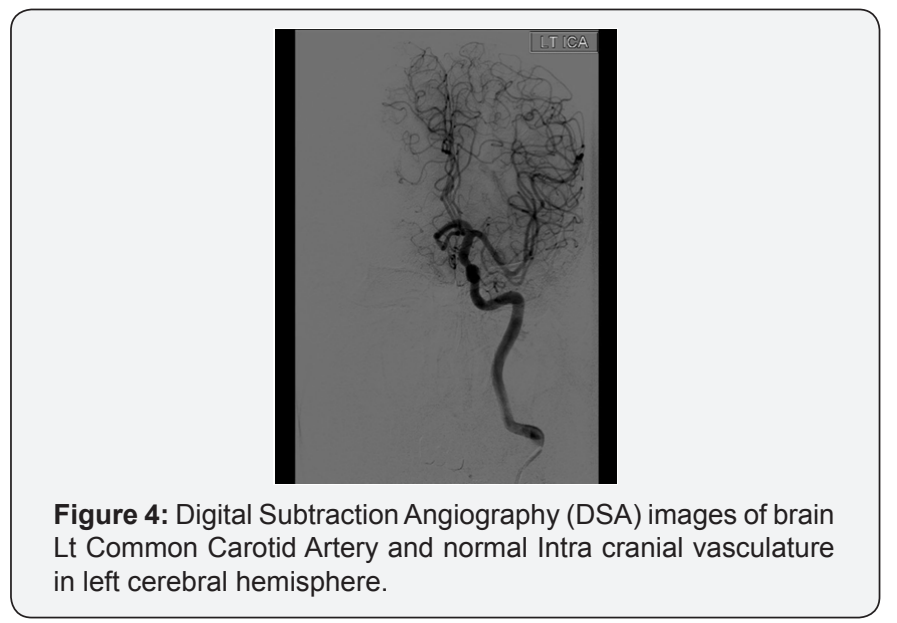

Blood investigations such as Anti-NuclearAntibodies (ANA), Anti-Nuclear Cytoplasmic Antibodies (ANCA), serological testing for syphilis fasting serum lipids, random blood sugars, fasting and post prandial blood sugars, serum electrolytes, renal function tests (creatinine, urea) and full blood count. Renal artery Doppler done as a work up for newly detected hypertension. All the above mentioned investigations were normal.

Differential Diagnosis considered were: Aneurysmal bleed; AV Malformation; Primary CNS Lymphoma. Patient was treated with antihypertensive, antiretroviral and speech therapy. The patient gradually improved partially and had improving motor aphasia at the time of discharge.

\section{Discussion}

ICH is a less common but known entity in young stroke in HIV and non-HIV patients. The common causes for intracerebral lobar bleeds are arterio-venous malformations, cavernomas, aneurysms, tumors like primary CNS Lymphoma, which bleed. Once these causes are ruled out, the other common cause of such lobar bleeds in HIV associated vasculopathy (HAV) [1].

HIV-induced amyloid deposition in cerebral vessels causing vasculopathy is a known cause of Intra cerebral bleed in HIV patients. Some evidence to that effect is found on multiple post autopsy histopathological studies, which have shown
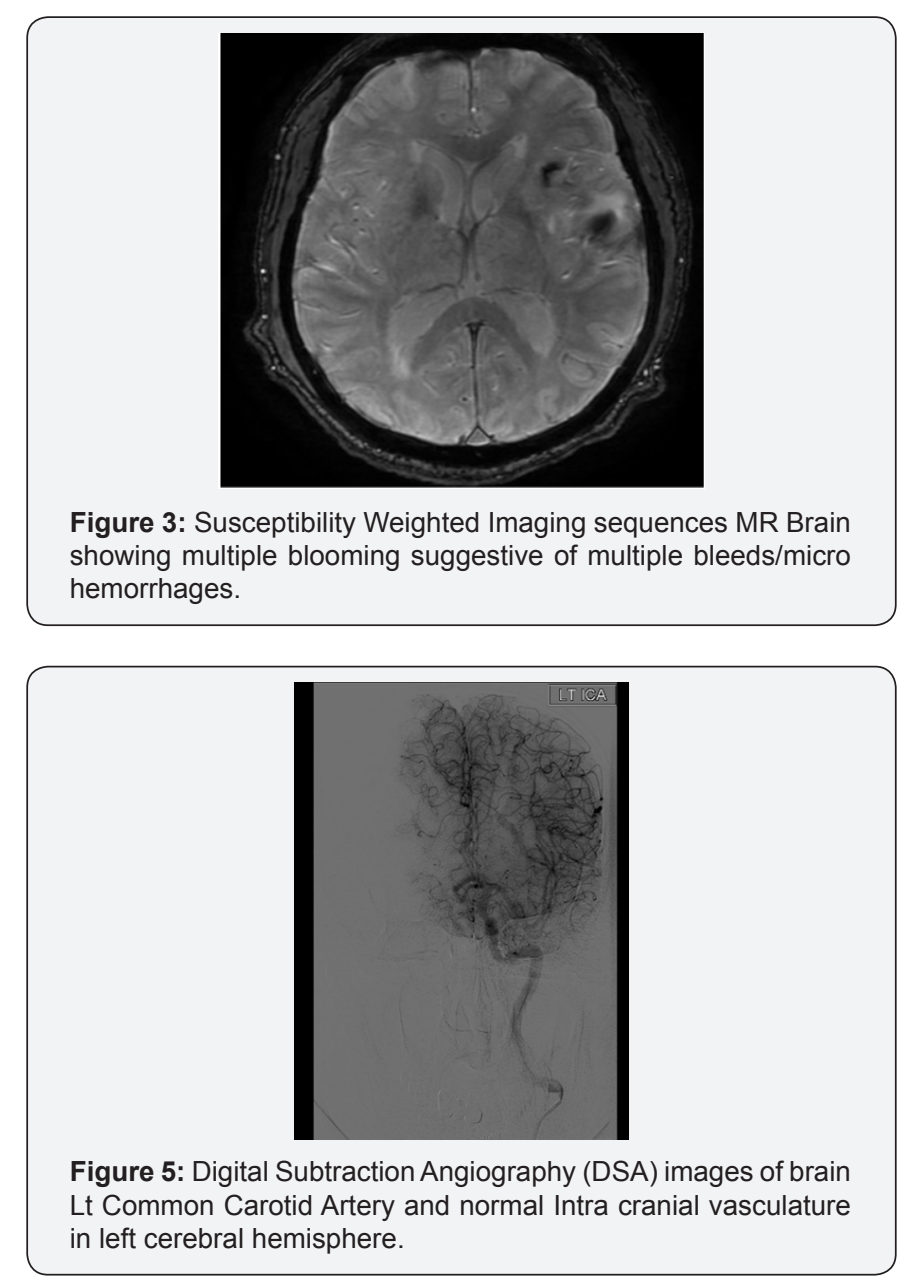

perivascular amyloid deposits in young HIV-positive individuals. Amyloid deposition in cerebral vessels increases the risk of ICH manifold [2,3].

MRI techniques such as T2-weighted gradient echo is frequently used to diagnose acute and chronic intra-cerebral bleeds, including micro bleeds [4]. Digital Subtraction Angiography (DSA) is an essential radiological tool to rule out arterio-venous malformations, aneurysms [5]. Although, intra cerebral bleeds have been reported in patients with HIV in the past, it is rare to have multiple bleeds (acute/sub acute/chronic) in the same cerebral hemisphere. This probably suggests that the new onset hypertension in addition to the existing underlying HIV Vasculopathy, could have been the most likely etiology behind these multiple, unilobar bleeds [6,7].

\section{Summary}

a) Intracerebral Hemorrhages (ICH) is less frequent cause of stroke than cerebral ischemia in patients with retroviral disease.

b) HIV associated Cerebral Amyloid Angiopathy should be considered as the possible cause for ICH after ruling out other causes such as AVM, Aneurysmal rupture, Primary CNS Lymphoma. 
c) T2 -weighted gradient-echo MRI is a useful for diagnosing older hemorrhages/micro bleeds.

\section{References}

1. Benjamin LA, Bryer A, Emsley HC, Khoo S, Solomon T, et al. (2012) HIV infection and stroke: current perspectives and future directions. Lancet Neurol 11(10): 878-890.

2. Chetty R, Batitang S, Nair R (2000) Large artery vasculopathy in HIVpositive patients: another vasculitic enigma. Hum Pathol 31(3): 374379.

3. Chetty R (2001) Vasculitides associated with HIV infection. J Clin Pathol 54(4): 275-278.
4. Ariesen MJ, Claus SP, Rinkel GJ, Algra A (2003) Risk factors for intracerebral hemorrhage in the general population: A systematic review. Stroke 34(8): 2060-2065.

5. Santhosh K, Kesavadas C, Thomas B, Gupta AK, Thamburaj K, et al. (2009) Susceptibility weighted imaging: a new tool in magnetic resonance imaging of stroke. Clin Radiol 64(1): 74-83.

6. Yu S, Yan L, Yao Y, Wang S, Yang M, et al. (2012) Noncontrast dynamic MRA in intracranial arteriovenous malformation (AVM): comparison with time of flight (TOF) and digital subtraction angiography (DSA) Magn Reson Imaging 30(6): 869-877.

7. Mochan A, Modi M, Modi G (2003) Stroke in black South African HIVpositive patients: a prospective analysis. Stroke 34(1): 10-15.

\begin{tabular}{l} 
Your next submission with Juniper Publishers \\
will reach you the below assets \\
- Quality Editorial service \\
- Swift Peer Review \\
- Reprints availability \\
- E-prints Service \\
- Manuscript Podcast for convenient understanding \\
- Global attainment for your research \\
- Manuscript accessibility in different formats \\
( Pdf, E-pub, Full Text, Audio) \\
- Unceasing customer service \\
Track the below URL for one-step submission \\
https://juniperpublishers.com/online-submission.php \\
\hline
\end{tabular}

